19 February 2020

Abstract: 247 words

Text: $\sim 4200$ words

Figures: 6

Tables: 3

References: 50

Supplements: 1

\title{
Adolescent Alcohol Use Disrupts Functional Neurodevelopment in Sensation Seeking Girls
}

Qingyu Zhao ${ }^{1}$, Edith V. Sullivan ${ }^{1}$, Eva Müller-Oehring ${ }^{1,2}$, Nicolas Honnorat ${ }^{2}$, Ehsan Adeli $^{1}$, Simon Podhajsky ${ }^{2}$, Fiona C. Baker ${ }^{2}$, Ian M. Colrain ${ }^{2}$, Devin Prouty ${ }^{2}$, Susan F. Tapert $^{3}$, Sandra A. Brown ${ }^{4,3}$, M.J. Meloy ${ }^{3}$, Ty Brumback ${ }^{5}$, Bonnie J. Nagel ${ }^{6}$, Angelica M. Morales $^{6}$, Duncan B. Clark ${ }^{7}$, Beatriz Luna ${ }^{7}$, Michael D. De Bellis ${ }^{8}$, James T. Voyvodic ${ }^{9}$, Adolf Pfefferbaum ${ }^{1,2}$, Kilian M. Pohl ${ }^{1,2}$

\author{
${ }^{1}$ Department of Psychiatry \& Behavioral Sciences, \\ Stanford University School of Medicine, Stanford, CA; \\ ${ }^{2}$ Center for Health Sciences, SRI International, Menlo Park, CA; \\ ${ }^{3}$ Department of Psychiatry and ${ }^{4}$ Department of Psychology, \\ University of California, San Diego, La Jolla, CA; \\ ${ }^{5}$ Department of Psychological Science, Northern Kentucky University, KY; \\ ${ }^{6}$ Departments of Psychiatry and Behavioral Neuroscience, \\ Oregon Health \& Sciences University, Portland, OR \\ ${ }^{7}$ Department of Psychiatry, University of Pittsburgh, Pittsburgh, PA; \\ ${ }^{8}$ Department of Psychiatry \& Behavioral Sciences and ${ }^{9}$ Department of Radiology, \\ Duke University School of Medicine, Durham, NC;
}

Keywords: Adolescence, Alcohol Use, Functional Imaging, Impulsivity, Neurodevelopment, Sexual Dimorphism

Running Title: Alcohol Effects on IFNs

\section{*Corresponding author}

Kilian M. Pohl, Ph.D.

Department of Psychiatry and Behavioral Sciences

Stanford University School of Medicine

401 Quarry Road Stanford,

CA 94305-5723

This is the author manuscript accepted for publication and has undergone full peer review but has not been through the copyediting, typesetting, pagination and proofreading process, which may lead to differences between this version and the Version of Record. Please cite this article as doi: $10.1111 / \mathrm{adb} .12914$

This article is protected by copyright. All rights reserved. 
phone: (650) 859-2182

FAX: (650) 859-2743

kilian.pohl@stanford.edu

\begin{abstract}
Exogenous causes, such as alcohol use, and endogenous factors, such as temperament and sex, can modulate developmental trajectories of adolescent neurofunctional maturation. We examined how these factors affect sexual dimorphism in brain functional networks in youth drinking below diagnostic threshold for Alcohol Use Disorder (AUD). Based on the 3-year, annually-acquired, longitudinal resting-state functional MRI data of 526 adolescents (12 - 21 years at baseline) from the National Consortium on Alcohol and Neurodevelopment in Adolescence (NCANDA) cohort, developmental trajectories of 23 intrinsic functional networks (IFN) were analyzed for 1) sexual dimorphism in 259 participants who were no-to-low drinkers throughout this period; 2) sex-alcohol interactions in two age- and sex-matched NCANDA subgroups ( $\mathrm{N}=76$ each), half no-to-low and half moderate-to-heavy drinkers; and 3) moderating effects of gender-specific alcohol dose effects and a multifactorial impulsivity measure on IFN connectivity in all NCANDA participants. Results showed that sex differences in no-to-low drinkers diminished with age in the inferior-occipital network, yet girls had weaker within-network connectivity than boys in six other networks. Effects of adolescent alcohol use were more pronounced in girls than boys in three IFNs. In
\end{abstract}


particular, girls showed greater within-network connectivity in two motor networks with more alcohol consumption, and these effects were mediated by sensation-seeking only in girls. Our results implied that drinking might attenuate the naturally diminishing sexual differences by disrupting the maturation of network efficiency more severely in girls. The sex-alcohol-dose effect might explain why women are at higher risk of alcohol-related health and psychosocial consequences than men.

\section{Introduction}

Adolescent brain development undergoes profound morphological and functional changes characterized by regional and temporal heterogeneity in growth trajectories ( 1 , 2). Structural magnetic resonance imaging (MRI) has revealed that gray matter volume declines, hypothesized to reflect synaptic pruning (3), while white matter volume increases from pre-adolescence (4) throughout adolescence into early adulthood (2) contributing to growth of the brain (4). Although gray matter pruning in certain regions might reflect changes in myelination affecting the appearance of gray-white matter boundaries in MRIs (3), white matter expansion is associated with functional connectivity enhancement contributing to efficient neural signaling and transmission $(2$, 5) and capacity for high-level cognition (6). Quantification of these neurobiological foundations of associated functional neuromaturation can be revealed through longitudinal analysis of whole-brain resting-state functional MRI (rs-fMRI). Analysis of 
rs-fMRI has identified multiple intrinsic functional networks (IFNs) (7) reflecting functionally connected brain regions. IFNs do not necessarily determine direct structural connections but do indicate brain regions exhibiting correlated functional activity. The organization of IFNs is established early in development while their remodeling and refinement continue with age (8).

Connectivity within functional networks of adolescents differs between the sexes (9) and can be altered by environmental agents, notably initiation of alcohol use (10), engaged by $33 \%$ of $12^{\text {th }}$ graders in the US (11). For example, the baseline study of rs-fMRI data by the National Consortium on Alcohol and NeuroDevelopment in Adolescence (NCANDA) (age 12-21 years at baseline) (12) revealed that girls exhibited weaker functional connectivity within the default mode, emotion, and salience networks than boys (13). The same study also showed that adolescents who exceeded a no-to-low drinking criterion had weaker functional connectivity with respect to networks seeded from the amygdala compared with adolescents with no-to-low alcohol use (13). This finding was echoed by a longitudinal study (14), in which lower left amygdalaorbitofrontal connectivity was associated with greater alcohol consumption within a two year period.

This article is protected by copyright. All rights reserved. 
A sex-alcohol interaction on functional brain development is likely as the adverse effect of alcohol consumption on physical and mental health may be more severe in women than men. Notably, the cognitive and motor impairment related to alcohol dependence was shown to be greater in women than men, and impairment presents in women at lower levels of alcohol consumption (15). Likewise, during adolescence, girls who engage in binge drinking transition to addiction more rapidly than boys, a phenomenon known as "telescoping" (15). While boys desisting from alcohol abuse after adolescence can function similarly to men without history of alcohol abuse (16), girls desisting from alcohol abuse after adolescence continue to suffer from negative alcohol-related health and psychosocial consequences (17).

These untoward female-oriented alcohol use effects have been linked to poorer impulse control in women compared with men at different life stages $(18,19)$. While impulsivity has been considered as a risk factor for both genders (20), mounting evidence has indicated that heavy drinking women displayed poorer impulse control than heavy drinking men during adulthood (21). Among adolescents, alcohol abuse has also been associated with higher sensation seeking levels (22). During this age period, sex differences emerge in the developmental trajectories of impulse control, and girls reach peak levels of sensation-seeking earlier than boys (23). Thus, impulse control may be 
relevant in explaining the differential effects of drinking on adolescent brain development between boys and girls.

To track development of sexual dimorphism in adolescent functional brain networks with respect to age, alcohol consumption, and impulsivity, we performed a novel voxel-wise analysis of IFNs (24) extracted from longitudinal rs-fMRI of 526 adolescents (12 - 21 years at baseline) scanned annually from the NCANDA cohort. First, we documented the sexual dimorphism in healthy functional brain development during adolescence in 259 youths (12 - 21 years at baseline) with no-to-low alcohol exposure. Next, we sought sex-alcohol interactions by comparing the IFNs in a subset of age- and sex-matched youth ( $\mathrm{N}=38 \mathrm{~F} / 38 \mathrm{M}$ no-to-low vs. 38F/38M moderate-to-heavy, 14-21 years at baseline) who were either moderate-to-heavy drinkers or no-to-low drinkers (24). Finally, the identified alcohol effects were related to the alcohol use history and impulsivity of the full NCANDA cohort, which also consisted of youth who transitioned from no-to-low to moderate-to-heavy drinkers within the 3-year study period (259 no-to-low,182 transitioning, 85 moderate-to-heavy drinkers). The analysis tested three principal hypotheses: (1) while younger boys have stronger within-network functional connectivity than younger girls, this sexual dimorphism diminishes with age; (2) with moderate-toheavy alcohol use, sexual dimorphism strengthens as girls also exhibit higher within- 
network connectivity than boys that is linked to greater disruption in network efficiency; and (3) the alcohol-related functional connectivity in girls is linked to impulsivity metrics.

\section{Materials and Methods}

\section{Participants}

The NCANDA cohort comprises 831 participants, ages 12 to 21 years at baseline and recruited across five collection sites: University of California at San Diego (UCSD), SRI International, Duke University Medical Center, University of Pittsburgh Medical Center, and Oregon Health \& Science University (OHSU). The Institutional Review Boards (IRB) of each site approved data collection and use (12). In compliance with NIH policy, the data releases NCANDA_PUBLIC_Y3_REDCAP_V01, NCANDA_PUBLIC_Y3_STRUCTURAL_V01 and NCANDA_PUBLIC_Y3_RESTINGSTATE_V01 have been made public according to the NCANDA Data Distribution agreement (see https://www.niaaa.nih.gov/research/majorinitiatives/national-consortium-alcohol-and-neurodevelopment-adolescence) $(25,26)$.

At baseline, 714 adolescents had usable rs-fMRI and structural scans (12), 584 of whom were classified as no-to-low drinkers according to the minimum drinking criteria of NCANDA based on the National Institute of Alcohol Abuse and Alcoholism (NIAAA) 
guidelines for risky drinking (see supplement Table S2 and Table 1 of (12)). These ageand sex-dependent criteria account for total days of drinking lifetime, maximum drinks per occasion, and other substance use (12). The remaining 130 youth that exceeded the drinking criteria but did not exceed marijuana and nicotine exposure criteria (12) were classified as moderate-to-heavy drinkers. None of the moderate-to-heavy drinkers participants met DSM 5 criteria (27) for Alcohol Use Disorder (AUD) at baseline observation.

By the $4^{\text {th }}$ year of the study, 526 adolescents had at least 3 annually-acquired usable rsfMRI scans (Fig. 1). Among this longitudinal cohort, 259 remained no-to-low drinkers throughout the study, 85 remained moderate-to-heavy drinkers, and 182 transited from no-to-low drinkers to moderate-to-heavy drinkers during the study. 5 of the 526 youth met criteria for mild AUD at one or more observations. Participants were characterized by age, sex, pubertal stage using the self-assessment Pubertal Development Scale (PDS), socioeconomic status as defined by the longest years of education from either parent, and the amount of exposure to nicotine and marijuana use (Table 1). To study sex-alcohol interactions, the dataset was matched with respect to scanner type $(p=0.99)$ and age (14 to 21 at baseline, $p>0.91$ ) across four groups (Table 1; Fig. 1): no-to-low drinking girls, no-to-low drinking boys, moderate-to-heavy drinking girls, and moderateto-heavy drinking boys. The matching algorithm (28) did so by ensuring that a maximum 
number of individuals would be selected per group and yielded 38 in each group (2 male and 2 female participants in the drinking group met mild AUD criteria).

---TABLE 1, FIGURE 1 ABOUT HERE---

\section{MRI Preprocessing}

The structural and resting-state data of all NCANDA participants were preprocessed using the publicly-available NCANDA pipeline (24), which included motion correction, outlier-detection, detrending, removing of physiological noise, and temporal and spatial smoothing. The pipeline then computed subject-specific intrinsic functional networks (IFNs) based on the 23 group-level IFNs identified by prior analysis on the NCANDA dataset (24). These IFNs were selected from 25 independent components that were derived by applying the Probabilistic ICA of MELODIC FSL V5.0.10 (29) to the preprocessed rs-fMRI images at baseline of the 584 no-to-low drinking youths. Of the 25 independent components, 23 were identified as IFNs commonly observed in other studies. The remaining two components were artifacts related to cerebrospinal fluid and motion. Guided by these group-level IFN estimates, 23 subject-specific IFNs were then derived for each of the 526 participants by the voxel-wise Longitudinal Independent Component Analysis (VL-ICA) (24). For each subject, each of the 23 subject-specific IFNs was encoded at each voxel by the average connectivity and slope (i.e. change in connectivity) across all visits. For example, negative slopes associated with positive average connectivity values encoded a reduction in functional connectivity over time. 
For each IFN, the corresponding average connectivity map was estimated by applying dual regression (29) to the concatenated rs-fMRI time series composed of all longitudinal scans of that subject. The slope map was estimated using VL-ICA (24). The supplement describes the MRI processing including the ICA approach in detail.

\section{Statistical Group Analysis}

Statistical testing was based on the subsets of the NCANDA data outlined in Figure 1. To test the first hypothesis, sex differences were identified at each voxel in the average connectivity maps and (separately) in the slope maps of 259 no-to-low drinkers by a GLM analysis with sex, age (at baseline), and scanner-type as covariates (see supplement for details). The resulting voxelwise $p$-values were corrected for spatial coherence by FSL TFCE (29), family-wise error (FWE) at the 5\% level, and Bonferroni corrected to account for testing across 23 networks. A two-tailed $p<0.05$ was viewed as significant. Detected clusters were confounded if their average functional connectivity or slope significantly correlated (uncorrected two-tailed $p<0.1$ ) with subject-specific motion or the number of rs-fMRI scans of each subject.

To test the last two hypotheses with respect to sex-alcohol interactions, alcohol effects were first identified separately for each gender on the matched dataset of 38 no-to-low drinkers and 38 moderate-to-heavy drinkers of that gender (14 - 21 years at baseline) (Fig. 1). The GLM analysis now replaced the sex covariate by the drinking group. Next, 
with sex as an additional covariate, alcohol effects were further identified on the whole matched dataset consisting of 76 no-to-low and 76 moderate-to-heavy drinkers for exploratory analysis. Clusters with significant alcohol-use effects from either analysis were further analyzed in the following.

\section{--- FIGURE 1 ABOUT HERE---}

To test the second hypothesis regarding the strengthening sexual dimorphism due to alcohol use, the mean value (average connectivity or slope) within each detected cluster was first residualized with respect to age (at baseline) and scanner by fitting a GLM on the no-to-low group. For each gender separately, two-sample t-tests (two-tailed $p<0.005$ ) identified the differences in the residuals across all three drinking groups (noto-low, transitioners, moderate-to-heavy; 248 girls / 278 boys). Then a two-way ANOVA $(p<0.005)$ identified significant interactions between sex and drinking-groups. The residuals were also correlated (two-tailed $p<0.005$ ) to the log of lifetime substance use averaged over visits (for average connectivity analysis) or the log of substance use between baseline and last visits (for slope). Tested substances included alcohol (the total days of drinking lifetime), nicotine (number of cigarettes consumed lifetime), and marijuana (days of using marijuana lifetime). Clusters with significant correlations to nicotine and marijuana exposure were omitted from analysis.

In line with the third hypothesis, clusters with significant sex-alcohol-dose effects were 
tested by the Baron and Kenny model (30) for medication effects $(p<0.005$, see supplement for test procedures). The model considered the impact of alcohol consumption on functional connectivity as a direct effect and impulsivity measures as a mediator of that effect. The impulsivity measures were the 5 UPPS-P (UrgencyPremeditation-Perseverance-Sensation Seeking-Positive Urgency) scores (31): negative urgency (NUG), positive urgency (PUG), lack of premeditation (PMT), lack of perseverance (PSV), and sensation seeking (SSS)). After residualizing each score for age at baseline, the average or the slope of each impulsivity score across all visits was used for mediation analysis.

\section{Results}

Sex Differences in Intrinsic Functional Connectivity. Based on the average connectivity analysis, boys exhibited greater functional connectivity within the positive hubs, i.e., regions with significant positive connectivity within a network, than girls. This effect occurred in 6 of the 23 IFNs, i.e., the dorsal default mode, auditory, inferior temporo-parieto-frontal, limbic hippocampal, emotion, and precuneus networks (Fig. 2, Table 2). Sex differences were also detected in the slope analysis at the bilateral lingual region of the inferior occipital network. With respect to this slope difference (Fig. 3), a post-hoc analysis revealed that while boys had higher average functional connectivity than girls in the detected cluster ( $p=0.05$, Fig. $3 b)$, they also had 
significantly steeper negative slopes indicating decreased connectivity over time $(p<0.005$, Fig. 3c). A linear mixed model fitted to the data showed that the functional connectivity was greater in boys during early adolescence, and this sex difference decreased as the connectivity in boys declined with aging (Fig. 3d). None of the negative hubs revealed significant sex effects.

\section{--- FIGURE 2, 3 AND TABLE 2 ABOUT HERE---}

Sex-Alcohol Interaction. The sex-specific matched-group analysis revealed that the 38 moderate-to-heavy drinking girls had significantly greater average functional connectivity in the precentral region of the sensorimotor medial network compared to the 38 no-to-low drinking girls (Fig. 4a, Table 3). Further analyzing this detected cluster on all girls of the NCANDA dataset, the average functional connectivity of the moderateto-heavy drinking girls $(\mathrm{N}=45)$ was greater than that of the female transitioners $(\mathrm{N}=94)$, and transitioners had average connectivity greater than no-to-low drinking girls ( $\mathrm{N}=139)$ (Fig. $4 b+c)$. Even though the comparison against the transitioners only showed trendlevel significance $(p<0.05)$, their intermediate position between no-to-low and moderateto-heavy drinkers suggested a graded dose effect. The graded effect was specific to girls on three accounts: 1) the graded pattern was not observed in boys; 2) the ANOVA test showed a significant sex/drinking-group interaction ( $p=0.0022)$; and 3 ) the moderate-to-heavy drinking girls had significantly greater connectivity than the 
moderate-to-heavy drinking boys ( $p=0.0009$, two-sample t-test, 45 girls vs. 40 boys), whereas the functional connectivity did not differ between boys and girls in the no-to-low drinking group. This female-specific alcohol effect was further supported by a significant correlation $(r=.182, p=0.0023)$ between the average functional connectivity and the log of the number of days of drinking lifetime among the girls with non-zero drinking history $(\mathrm{N}=186)$ (Fig. 4d).

The partial mediation analysis also revealed a significant indirect effect $(p<0.001$, Fig. 4e) of sensation seeking on the association between alcohol consumption and functional connectivity. Neither the alcohol dose effects nor the mediation effects of the impulsivity scores were significant in boys. Further, the average functional connectivity in the detected cluster did not show significant correlations with nicotine or marijuana exposure.

\section{--- FIGURE 4 AND TABLE 3 ABOUT HERE---}

Exploratory Analysis of Alcohol Use Effects. The 76 matched moderate-to-heavy drinkers exhibited greater average functional connectivity than the matched no-to-low group in the motor network (Fig. 5a, Table 3). The significant cluster encompassed the precentral, postcentral, and supramarginal regions according to the SRI24 atlas (32). With respect to this detected cluster, the average functional connectivity showed a graded effect among the three drinking groups within each sex (248 girls / 278 boys), 
with the moderate-to-heavy drinking group having the highest average functional connectivity and no-to-low drinkers having the lowest (Fig. $5 b+c)$. Meanwhile, girls with non-zeros drinking history exhibited a significant correlation $(r=.20, p<0.0001)$ between the average functional connectivity and the log of the number of days of drinking lifetime, whereas boys showed only a trend-level $(r=.134, p=0.017)$ correlation (Fig. $5 d$ ). The findings of the mediation analysis were confined to a trend-level effect of sensation seeking ( $p=0.04)$ in girls (Fig. $5 e$ ) and insignificant for all 5 UPPS-P scores in boys.

\section{--- FIGURE 5 ABOUT HERE---}

Slope analysis on the matched groups revealed that the 76 moderate-to-heavy drinkers had a significantly steeper negative slope than the 76 no-to-low drinkers in the precentral and postcentral regions of the inferior temporo-parieto-frontal network (Fig. $6 a$, Table 3). Analysis confined to that region within each sex revealed that all three drinking groups had significantly negative slopes (one-sample t-tests $p<0.001$ ) with a graded effect for both genders. Among the three cohorts, the slope in the no-to-low group was the flattest, the slope in the moderate-to-heavy drinking group was the steepest $($ Fig. $6 b+c)$. Both boys and girls exhibited a significant negative correlation between the slope and the log of the number of days of drinking between baseline and last visit (Fig. $6 d$, boys: $r=.210, p=0.0008$; girls: $r=.187, p=0.0002$ ), i.e., the higher that number for a person, the greater the decline in functional connectivity in the precentral 
and postcentral regions as the adolescent gets older. No sex-specific mediation effect was observed for the five UPPSP-scores. Also, none of the detected clusters in the exploratory analysis was significantly correlated with nicotine or marijuana exposure.

\section{--- FIGURE 6 ABOUT HERE---}

\section{Discussion}

In support of the first hypothesis, sexual dimorphism diminished with normal development. Specifically, voxelwise, longitudinal analysis revealed that while boys exhibited stronger functional connectivity within IFN hubs than girls in young adolescence, this difference narrowed with age. The second hypothesis on the sexalcohol interaction was supported by the female-specific graded alcohol effects found in the sensorimotor medial network. In support of the third hypothesis, only in girls was sensation seeking a significant partial mediator of the alcohol effect on the sensorimotor medial network and a trend-level mediator on the motor network.

Our longitudinal findings refined region-of-interest studies (33) through a voxel-wise analysis, which examined the hub regions in the spatial (average or slope) maps of each IFN quantifying within-network functional connectivity. While studies largely agree that girls have stronger across-network connectivity than boys $(9,33)$, reports on withinnetwork sex dimorphism lack consistency. Several adolescent and adult rs-fMRI studies have documented stronger within-network connectivity for girls in selective IFNs but 
stronger connectivity for boys in other networks (34). Our analysis instead revealed a consistent pattern on the NCANDA dataset, where boys always had significantly higher connectivity than girls in the 6 IFNs with sex effects. Higher connectivity inside hubs was previously detected for the older relative to younger adolescents of NCANDA in cross-sectional study (24) suggesting that, regardless of gender, functional networks become more specialized towards specific cognitive functioning as adolescence advances (35).

Notably, our novel longitudinal analysis revealed developmental trajectories that refined the cross-sectional findings on sex differences in functional connectivity within the lingual region (36) (and more general within the occipital cortex (37)) across the life span. In early adolescence, the NCANDA girls exhibited lower functional connectivity in the lingual region of the inferior occipital network than boys. As girls grew older their functional connectivity stayed almost constant. By contrast, boys exhibited a significant negative trajectory supporting the hypothesis based on our cross-sectional baseline findings (13) that sexual dimorphism in functional connectivity diminishes with developmental progression through later adolescence.

Normal functional development of the brain can be disrupted by initiation of drinking during adolescence. Our analyses showed that alcohol effects on the functional 
connectivity are different between sexes and invert the diminishing sexual dimorphism in normal functional development even with alcohol consumption that does not rise to the level of an AUD diagnosis. Specifically, the present longitudinal analysis identified alcohol-related modulation in precentral and postcentral regions of the inferior temporoparieto-frontal network (slope) and of the sensorimotor and motor networks (average connectivity). Evidence from neurobiological studies suggests that the major role of sensorimotor circuits is to allow for development and control of novel or non-innate actions sequences, also referred to as instrumental learning (38). In relation to alcohol abuse and addiction, the sensorimotor circuit contributes to the control of habitual and instrumental actions related to alcohol seeking and taking (38). In addition, functional MRI studies have frequently linked the alternations in both sensorimotor and motor networks with excessive alcohol and nicotine abuse and substance use disorders in adults (39-41). In line with our results, Wang and colleagues also found increased functional connectivity in the motor area in adults with alcohol and other substance use dependencies (40). They suggested that such hyper-connectivity was accompanied by a loss of inhibition in addiction potentially due to the fact that the elevated dynamic resting state is an indication of higher wiring cost and lower communication efficiency resulting in difficulty in inhibition. While our analysis has not revealed sex differences in the two motor networks in the no-to-low cohort, other studies have documented sex 
differences in these networks (42), which could potentially explain why these two networks were preferentially affected by alcohol differently between boys and girls.

While alcohol abuse was traditionally regarded as a male-oriented problem, recent studies have highlighted the fact that female youth may be more vulnerable to alcohol misuse than male youth (15). Mounting evidence links such sexual dimorphism to the differential alcohol effects on the organization of the neural systems and their functioning (43). For example, stronger effects of alcohol on the working memory and the functional connectivity associated with the vigilance tasks have been reported for female adolescents with AUD compared to their male counterparts (44). In support of this growing literature, our analysis on the NCANDA data revealed a stronger (graded) alcohol dose effect for girls with respect to the average functional connectivity of the sensorimotor medial network despite girls having drunk less than boys (Table 1 ). Unlike the diminishing or diminished sex difference in the no-to-low drinkers, the moderate-toheavy drinking girls had significantly greater connectivity than the moderate-to-heavy drinking boys suggesting an accentuated sexual dimorphism related to alcohol use. The stronger functional connectivity in pre- and postcentral regions within motor and sensorimotor networks in the moderate-to-heavy drinking girls was accompanied by a weakening of functional connectivity within the inferior temporo-parieto-frontal network. Thus, even sub-threshold AUD alcohol consumption during adolescence in girls 
appears to affect how these regions intrinsically connect to specific networks and is opposing to that of no-to-low drinking adolescents, whose neural networks become more efficient with maturation, requiring less functional activation over time (45). As mentioned above, stronger functional connectivity in the network hubs has been suggested to be a compensatory mechanism in alcohol use disorder and drug dependence that usurps cognitive resources to counteract impairment in neural functioning such as higher wiring cost and lower efficiency (46, 47). However, stronger functional connectivity might also reflect a neural risk factor where a strengthening of sensorimotor connections in relation to alcohol facilitates impulsive response patterns, including sensation seeking behaviors. For example, Shannon and colleagues (48) found that increased functional connectivity of motor-planning regions with networks associated with self-referential cognition heightens the predisposition to impulsive behavior.

Sensation seeking linked sexual dimorphism and the alcohol effect on the two motor networks (motor and sensorimotor). Studies have documented that heavy drinking women display poorer impulsive control than heavy drinking men, thus leading to problematic alcohol consumption in women (21). Our analysis found that the correlation for alcohol use and impaired functional connectivity was partially mediated by sensation seeking in girls and was much weaker in boys. This female-specific disruption in the 
development of functional networks during adolescence contributes to our understanding of the higher risk to negative alcohol-related health and psychosocial problems in women later in life (15).

Relevant to our findings on the alcohol-related sex differences is that factors related to heavy drinking in women are mostly associated with regulating negative affect and the experience of negative (i.e., negative reinforcement) while factors for men are mostly associated with enhancing positive emotions (i.e., positive reinforcement) (49). For example, the impact of early drinking onset on anxiety and depression symptoms and has been reported to be stronger for girls than for boys, and initial depressive symptoms during early adolescence in girls have been associated with increased problematic alcohol use later in adolescence (50). In our analysis, the UPPS-P measures related to negative and positive reinforcement (i.e. negative and positive urgency) did not reveal any significant effect. However, we identified a negative reinforcement effect with respect to alcohol drinking in girls when extending the mediation analysis to the "relaxation and tension reduction" score from the Alcohol Expectancy Questionnaire (12). Reflecting the extent to which participants attribute relaxation and tension reduction as outcomes of drinking, the mediation effect of the score was significant only for girls on the motor network ( $p<0.0001$, Fig. S1 in supplement). 
Limitation: The current analysis largely depended on correlation analysis. What remains to be explored is the causal direction between factors, i.e., the possibility that abnormal functional connectivity can trigger impulsive behaviors to seek alcohol use, or conversely, that normal functional development is vulnerable to even moderate to heavy but non-dependent levels of alcohol consumption. Likewise, it remains to be determined whether sex differences in impulsive control are the result of differential neural vulnerability to alcohol consumption, or whether they pre-date the problematic drinking in individuals. Finally, the analysis still needs to track functional repairment following abstinence from heavy drinking based on participants that transitioned from moderateheavy to no-low drinking, which was the case for only 8 NCANDA subjects by Year 4 of the study but we anticipate to increase in later years. Such analysis could identify reversible or persistent alcohol-related injury on the functional neurodevelopment during adolescence.

\section{Conclusion}

Our longitudinal rs-fMRI analysis identified sex differences in intrinsic functional connectivity within 6 of 23 IFNs in adolescents. Based on analyzing annually-acquired, longitudinal rs-fMRI of 259 adolescents that met no-to-low drinking criteria, girls had weaker within-network functional connectivity inside the hub regions than boys, and such sex difference diminished in the inferior occipital network with age. Our study also showed that sub-threshold AUD alcohol consumption accentuated sexual dimorphism in 
the sensorimotor network, where alcohol effects were specific to girls, and sensation seeking may be a major underlying behavioral mechanism for differential alcohol effects between sexes.

Disclosures and acknowledgments: None of the authors have biomedical financial interests or conflicts of interest with the reported data or their interpretation. This work was supported by the U.S. National Institute on Alcohol Abuse and Alcoholism with cofunding from the National Institute on Drug Abuse, the National Institute of Mental Health, and the National Institute of Child Health and Human Development [NCANDA grant numbers: AA021697 (AP+KMP), AA021695 (SFT+SAB), AA021692 (SFT), AA021696 (IMC+FCB), AA021681 (MDDB), AA021690 (DBC), AA021691 (BJN)]; AA010723 (EVS)

Authors Contribution: Q.Z. processed data, performed analysis and wrote the manuscript. K.M.P. contributed to the data processing. E.V.S., E. M.O., A.P., K.M.P. interpreted results and contributed to the writing. N.H., E.A., S.P., F.C.B., I.M.C., D.P., S.F.T., S.A.B., M.J.M., T.B., B.J.N., A.M.M., D.B.C., B.L., M.D.D. J.T.V. contributed to the study design and writing. 


\section{Reference}

1. Petrican R, Taylor MJ, Grady CL. Trajectories of brain system maturation from childhood to older adulthood: Implications for lifespan cognitive functioning. Neuroimage. 2017;163:125-149. 2. Giedd JN. Structural magnetic resonance imaging of the adolescent brain. Ann N Y Acad Sci. 2004;1021:77-85.

3. Natu VS, Gomez J, Barnett M, Jeska B, Kirilina E, Jaeger C, Zhen Z, Cox S, Weiner KS, Weiskopf N, Grill-Spector K. Apparent thinning of human visual cortex during childhood is associated with myelination. Proc Natl Acad Sci U S A. 2019;116:20750-20759.

4. Pfefferbaum A, Mathalon DH, Sullivan EV, Rawles JM, Zipursky RB, Lim KO. A quantitative magnetic resonance imaging study of changes in brain morphology from infancy to late adulthood. Arch Neurol. 1994;51:874-887.

5. Feinberg I. Cortical pruning and the development of schizophrenia. Schizophr Bull. 1990;16:567-570.

6. Simmonds DJ, Hallquist MN, Asato M, Luna B. Developmental stages and sex differences of white matter and behavioral development through adolescence: a longitudinal diffusion tensor imaging (DTI) study. Neuroimage. 2014;92:356-368.

7. Buckner RL, Krienen FM, Yeo BT. Opportunities and limitations of intrinsic functional connectivity MRI. Nat Neurosci. 2013;16:832-837.

8. Marek S, Hwang K, Foran W, Hallquist MN, Luna B. The Contribution of Network Organization and Integration to the Development of Cognitive Control. PLoS Biol. 2015;13:e1002328.

9. Alarcón G, Cservenka A, Rudolph MD, Fair DA, Nagel BJ. Developmental sex differences in resting state functional connectivity of amygdala sub-regions. Neuroimage. 2015;115:235-244. 10. Squeglia LM, Gray KM. Alcohol and Drug Use and the Developing Brain. Curr Psychiatry Rep. 2016;18:46.

11. Patrick ME, Terry-McElrath YM, Schulenberg JE, Bray BC. Patterns of high-intensity drinking among young adults in the United States: A repeated measures latent class analysis. Addict Behav. 2017;74:134-139.

12. Brown SA, Brumback T, Tomlinson K, Cummins K, Thompson WK, Nagel BJ, De Bellis MD, Hooper SR, Clark DB, Chung T, Hasler BP, Colrain IM, Baker FC, Prouty D, Pfefferbaum A, Sullivan EV, Pohl KM, Rohlfing T, Nichols BN, Chu W, Tapert SF. The National Consortium on Alcohol and NeuroDevelopment in Adolescence (NCANDA): A Multisite Study of Adolescent Development and Substance Use. J Stud Alcohol Drugs. 2015;76:895-908. 13. Muller-Oehring EM, Kwon D, Nagel BJ, Sullivan EV, Chu W, Rohlfing T, Prouty D, Nichols BN, Poline JB, Tapert SF, Brown SA, Cummins K, Brumback T, Colrain IM, Baker FC, De Bellis MD, Voyvodic JT, Clark DB, Pfefferbaum A, Pohl KM. Influences of Age, Sex, and Moderate Alcohol Drinking on the Intrinsic Functional Architecture of Adolescent Brains. Cereb Cortex. 2018;28:1049-1063. 
14. Peters S, Peper JS, Van Duijvenvoorde ACK, Braams BR, Crone EA. Amygdalaorbitofrontal connectivity predicts alcohol use two years later: a longitudinal neuroimaging study on alcohol use in adolescence. Dev Sci. 2017;20.

15. Dir AL, Bell RL, Adams ZW, Hulvershorn LA. Gender Differences in Risk Factors for Adolescent Binge Drinking and Implications for Intervention and Prevention. Front Psychiatry. 2017;8:289.

16. Hicks BM, Iacono WG, McGue M. Consequences of an adolescent onset and persistent course of alcohol dependence in men: adolescent risk factors and adult outcomes. Alcohol Clin Exp Res. 2010;34:819-833.

17. Foster KT, Hicks BM, Iacono WG, McGue M. Alcohol use disorder in women: Risks and consequences of an adolescent onset and persistent course. Psychol Addict Behav. 2014;28:322335.

18. Townshend JM, Duka T. Binge drinking, cognitive performance and mood in a population of young social drinkers. Alcohol Clin Exp Res. 2005;29:317-325.

19. Nederkoorn C, Baltus M, Guerrieri R, Wiers RW. Heavy drinking is associated with deficient response inhibition in women but not in men. Pharmacol Biochem Behav. 2009;93:331336.

20. Ide JS, Zhornitsky S, Hu S, Zhang S, Krystal JH, Li CR. Sex differences in the interacting roles of impulsivity and positive alcohol expectancy in problem drinking: A structural brain imaging study. Neuroimage Clin. 2017;14:750-759.

21. Weafer J, De Arcangelis J, de Wit H. Sex differences in behavioral impulsivity in at-risk and non-risk drinkers. Front Psychiatry. 2015;6:72.

22. Beyers JM, Toumbourou JW, Catalano RF, Arthur MW, Hawkins JD. A cross-national comparison of risk and protective factors for adolescent substance use: the United States and Australia. J Adolesc Health. 2004;35:3-16.

23. Shulman EP, Harden KP, Chein JM, Steinberg L. Sex differences in the developmental trajectories of impulse control and sensation-seeking from early adolescence to early adulthood. J Youth Adolesc. 2015;44:1-17.

24. Zhao Q, Kwon D, Müller-Oehring EM, Le Berre AP, Pfefferbaum A, Sullivan EV, Pohl KM. Longitudinally consistent estimates of intrinsic functional networks. Hum Brain Mapp. 2019;40:2511-2528.

25. Nichols BN, Pohl KM. Neuroinformatics Software Applications Supporting Electronic Data Capture, Management, and Sharing for the Neuroimaging Community. Neuropsychol Rev. 2015;25:356-368.

26. Rohlfing T, Cummins K, Henthorn T, Chu W, Nichols BN. N-CANDA data integration: anatomy of an asynchronous infrastructure for multi-site, multi-instrument longitudinal data capture. J Am Med Inform Assoc. 2014;21:758-762.

27. Association AP: Diagnostic and statistical manual of mental disorders (5th ed.). Arlington, VA, American Psychiatric Publishing; 2013. 
28. Adeli E, Kwon D, Zhao Q, Pfefferbaum A, Zahr NM, Sullivan EV, Pohl KM. Chained regularization for identifying brain patterns specific to HIV infection. Neuroimage. 2018;183:425-437.

29. Jenkinson M, Beckmann CF, Behrens TE, Woolrich MW, Smith SM. Fsl. Neuroimage. 2012;62:782-790.

30. Baron RM, Kenny DA. The moderator-mediator variable distinction in social psychological research: conceptual, strategic, and statistical considerations. J Pers Soc Psychol. 1986;51:11731182.

31. Coskunpinar A, Dir AL, Cyders MA. Multidimensionality in impulsivity and alcohol use: a meta-analysis using the UPPS model of impulsivity. Alcohol Clin Exp Res. 2013;37:1441-1450. 32. Rohlfing T, Zahr NM, Sullivan EV, Pfefferbaum A. The SRI24 multichannel atlas of normal adult human brain structure. Hum Brain Mapp. 2010;31:798-819.

33. Satterthwaite TD, Wolf DH, Roalf DR, Ruparel K, Erus G, Vandekar S, Gennatas ED, Elliott MA, Smith A, Hakonarson H, Verma R, Davatzikos C, Gur RE, Gur RC. Linked Sex Differences in Cognition and Functional Connectivity in Youth. Cereb Cortex. 2015;25:23832394.

34. Teeuw J, Brouwer RM, Guimarães JPOF, Brandner P, Koenis MMG, Swagerman SC, Verwoert M, Boomsma DI, Hulshoff Pol HE. Genetic and environmental influences on functional connectivity within and between canonical cortical resting-state networks throughout adolescent development in boys and girls. Neuroimage. 2019:116073.

35. Fair DA, Cohen AL, Dosenbach NU, Church JA, Miezin FM, Barch DM, Raichle ME, Petersen SE, Schlaggar BL. The maturing architecture of the brain's default network. Proc Natl Acad Sci U S A. 2008;105:4028-4032.

36. Keller K, Menon V. Gender differences in the functional and structural neuroanatomy of mathematical cognition. Neuroimage. 2009;47:342-352.

37. Cao W, Sun X, Dong D, Yao S, Huang B. Sex Differences in Spontaneous Brain Activity in Adolescents With Conduct Disorder. Front Psychol. 2018;9:1598.

38. Gremel CM, Lovinger DM. Associative and sensorimotor cortico-basal ganglia circuit roles in effects of abused drugs. Genes Brain Behav. 2017;16:71-85.

39. Vergara VM, Liu J, Claus ED, Hutchison K, Calhoun V. Alterations of resting state functional network connectivity in the brain of nicotine and alcohol users. Neuroimage. 2017;151:45-54.

40. Wang Z, Suh J, Li Z, Li Y, Franklin T, O'Brien C, Childress AR. A hyper-connected but less efficient small-world network in the substance-dependent brain. Drug Alcohol Depend. 2015;152:102-108.

41. Weiland BJ, Sabbineni A, Calhoun VD, Welsh RC, Bryan AD, Jung RE, Mayer AR, Hutchison KE. Reduced left executive control network functional connectivity is associated with alcohol use disorders. Alcohol Clin Exp Res. 2014;38:2445-2453.

42. Gur RC, Richard J, Calkins ME, Chiavacci R, Hansen JA, Bilker WB, Loughead J, Connolly JJ, Qiu H, Mentch FD, Abou-Sleiman PM, Hakonarson H, Gur RE. Age group and sex 
differences in performance on a computerized neurocognitive battery in children age 8-21. Neuropsychology. 2012;26:251-265.

43. Hu S, Ide JS, Chao HH, Zhornitsky S, Fischer KA, Wang W, Zhang S, Li CR. Resting state functional connectivity of the amygdala and problem drinking in non-dependent alcohol drinkers. Drug Alcohol Depend. 2018;185:173-180.

44. Tapert SF, Schweinsburg AD, Barlett VC, Brown SA, Frank LR, Brown GG, Meloy MJ. Blood oxygen level dependent response and spatial working memory in adolescents with alcohol use disorders. Alcohol Clin Exp Res. 2004;28:1577-1586.

45. Luna B, Padmanabhan A, O'Hearn K. What has fMRI told us about the development of cognitive control through adolescence? Brain Cogn. 2010;72:101-113.

46. Zhu X, Cortes CR, Mathur K, Tomasi D, Momenan R. Model-free functional connectivity and impulsivity correlates of alcohol dependence: a resting-state study. Addict Biol. 2017;22:206-217.

47. Jansen JM, van Holst RJ, van den Brink W, Veltman DJ, Caan MW, Goudriaan AE. Brain function during cognitive flexibility and white matter integrity in alcohol-dependent patients, problematic drinkers and healthy controls. Addict Biol. 2015;20:979-989.

48. Shannon BJ, Raichle ME, Snyder AZ, Fair DA, Mills KL, Zhang D, Bache K, Calhoun VD, Nigg JT, Nagel BJ, Stevens AA, Kiehl KA. Premotor functional connectivity predicts impulsivity in juvenile offenders. Proc Natl Acad Sci U S A. 2011;108:11241-11245.

49. Peltier MR, Verplaetse TL, Mineur YS, Petrakis IL, Cosgrove KP, Picciotto MR, McKee SA. Sex differences in stress-related alcohol use. Neurobiol Stress. 2019;10:100149.

50. Edwards AC, Heron J, Dick DM, Hickman M, Lewis G, Macleod J, Kendler KS. Adolescent alcohol use is positively associated with later depression in a population-based U.K. cohort. J Stud Alcohol Drugs. 2014;75:758-765. 
Table 1

Demographic characteristics of the 714 NCANDA subjects with usable baseline scans and 526 subjects with at least 3 usable scans by year 4. Two subgroups of 76/76 subjects that were matched on age, sex and scanner type were drawn from the 526 longitudinal cohort.

\begin{tabular}{|c|c|c|c|c|c|c|c|}
\hline & \multicolumn{3}{|c|}{ Whole Longitudinal } & \multicolumn{2}{|c|}{ Matched Longitudinal } \\
\hline & & & No-to-low & Transitioner & $\begin{array}{c}\text { Moderate-to- } \\
\text { heavy }\end{array}$ & No-to-low & $\begin{array}{l}\text { Moderate-to- } \\
\text { heavy }\end{array}$ \\
\hline \multicolumn{3}{|c|}{ \# of adolescents (Boys/Girls) } & 259(120/139) & 182(88/94) & $85(40 / 45)$ & $76(38 / 38)$ & $76(38 / 38)$ \\
\hline \multirow{2}{*}{\multicolumn{2}{|c|}{ Age }} & Girls & $15.6 \pm 2.3$ & $16.9 \pm 2.1$ & $18.4 \pm 2.0$ & $17.7 \pm 2.0$ & $18.1 \pm 2.0$ \\
\hline & & Boys & $15.3 \pm 2.4$ & $16.7 \pm 2.0$ & $18.3 \pm 1.7$ & $17.9 \pm 1.9$ & $18.2 \pm 1.7$ \\
\hline \multicolumn{3}{|c|}{ Scanner (GE/Siemens) } & $157 / 102$ & $129 / 53$ & $56 / 29$ & $47 / 29$ & $47 / 29$ \\
\hline \multicolumn{3}{|c|}{ Pubertal Development Scale } & $3.14 \pm 0.7$ & $3.37 \pm 0.6$ & $3.63 \pm 0.4$ & $3.54 \pm 0.5$ & $3.60 \pm 0.4$ \\
\hline \multicolumn{3}{|c|}{ Parental education (years) } & $16.66 \pm 2.4$ & $17.10 \pm 2.4$ & $17.18 \pm 2.3$ & $16.7 \pm 2.0$ & $17.2 \pm 2.3$ \\
\hline \multirow{2}{*}{\multicolumn{2}{|c|}{$\begin{array}{l}\text { Days of drinking } \\
\text { lifetime (by year 4) }\end{array}$}} & Girls & $2.8 \pm 7.2$ & $56.1 \pm 68.6$ & $127.3 \pm 93.6$ & $3.2 \pm 5.3$ & $72.8 \pm 58.4$ \\
\hline & & Boys & $3.4 \pm 8.2$ & $59.2 \pm 75.6$ & $166.7 \pm 157.6$ & $3.2 \pm 6.3$ & $102.1 \pm 107.0$ \\
\hline \multirow{2}{*}{\multicolumn{2}{|c|}{$\begin{array}{l}\text { Days of drinking } \\
\text { between baseline } \\
\text { and last visit }\end{array}$}} & Girls & $2.6 \pm 6.8$ & $54.5 \pm 67.3$ & $123.4 \pm 96.0$ & $6.1 \pm 10.8$ & $94.7 \pm 70.0$ \\
\hline & & Boys & $3.1 \pm 7.5$ & $57.5 \pm 73.1$ & $123.4 \pm 118.9$ & $6.1 \pm 10.8$ & $125.47 \pm 120.8$ \\
\hline \multirow[t]{2}{*}{ Nicotine } & \multirow{2}{*}{\multicolumn{2}{|c|}{$\begin{array}{l}\text { \# of cigarettes } \\
\text { lifetime } \\
\text { \# of cigarettes } \\
\text { between } \\
\text { baseline and } \\
\text { last visit }\end{array}$}} & & $79.9 \pm 803.7$ & $95.4 \pm 283.3$ & & \\
\hline & & & $0.64 \pm 7.5$ & $79.4 \pm 803.6$ & $81.8 \pm 260.2$ & $0.64 \pm 7.5$ & $81.1 \pm 260.3$ \\
\hline \multirow[t]{2}{*}{ Marijuana } & \multirow{2}{*}{\multicolumn{2}{|c|}{$\begin{array}{l}\text { days lifetime } \\
\text { days between } \\
\text { baseline and } \\
\text { last visit }\end{array}$}} & $1.78 \pm 16.9$ & $62.95 \pm 145.7$ & $157.3 \pm 350.0$ & $1.99 \pm 16.3$ & $174.4 \pm 366.5$ \\
\hline & & & $1.67 \pm 16.7$ & $61.86 \pm 144.7$ & $106.14 \pm 235.1$ & $1.84 \pm 16.0$ & $117.80 \pm 246.1$ \\
\hline
\end{tabular}

This article is protected by copyright. All rights reserved. 
Table 2.

Sex effects on the average functional connectivity maps and the slope detected on the longitudinal rs-fMRI data associated with 259 no-to-low drinkers in the NCANDA study. For each detected cluster, the name of network, number of voxels meeting the $p$-value threshold (FWE corrected), minimum p-value inside the cluster, and the ROI name at the location of minimum p-value are displayed. Networks were specified in (24). ROI names were specified according to the SRI24 atlas (32).

\begin{tabular}{|c|c|c|c|c|}
\hline & Network & \# of voxels & $\begin{array}{l}\text { Min p-value } \\
\text { (corrected) }\end{array}$ & ROI at min $p$-value \\
\hline \multirow{6}{*}{ 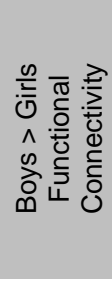 } & Dorsal Default Mode Network & 1164 & 0.004 & Frontal_Sup_Medial \\
\hline & Auditory Network & 1945 & 0.009 & Heschl $^{-}-$ \\
\hline & $\begin{array}{l}\text { Inferior Temporo-Parieto-Frontal } \\
\text { Network }\end{array}$ & 151 & 0.009 & Temporal_Sup_L \\
\hline & Precuneus Network & 132 & 0.026 & Precuneus \\
\hline & Emotion Network & 447 & 0.004 & Temporal_Pole_L \\
\hline & Limbic Hippocampal Network & 657 & 0.004 & Insula_L ${ }^{-}-$ \\
\hline & Inferior Occipital Network & 150 & 0.013 & Lingual \\
\hline
\end{tabular}

This article is protected by copyright. All rights reserved. 
Table 3.

Alcohol effects detected on the longitudinal rs-fMRI data of the matched dataset.

$\begin{array}{llll}\text { Difference Network } & \begin{array}{l}\text { \# of } \\ \text { voxels }\end{array} & \begin{array}{l}\text { Min p-value } \\ \text { (corrected) }\end{array} & \text { Group Overlapping ROIs } \\ \text { Average } & & & \end{array}$

\section{Connectivity}

No-to-low

Sensorimotor

229

0.04

F only

Precentral_R

$<$ Moderate- Network (medial)

to-heavy

\section{No-to-low}

$<$ exceeds

Motor Network

101

0.022

$M+F$

Frontal_Sup_R Supp_Motor_Area_R Postcentral_R Paracentral_Lobule_R

Slope

\begin{tabular}{|c|c|c|c|c|c|}
\hline $\begin{array}{l}\text { No-to-low } \\
<\text { Moderate- } \\
\text { to-heavy }\end{array}$ & $\begin{array}{l}\text { Inferior Temporo- } \\
\text { Parieto-Frontal } \\
\text { Network }\end{array}$ & 76 & 0.004 & $M+F$ & $\begin{array}{l}\text { Postcentral_L } \\
\text { Precetral_L }\end{array}$ \\
\hline
\end{tabular}

This article is protected by copyright. All rights reserved. 


\section{Figure Legends}

Fig 1. Of the 714 NCANDA participants with usable baseline rs-fMRI scans, the longitudinal analysis of intrinsic functional networks (IFNs) was over the 526 participants that had 3-4 annually acquired scans. The analysis examined 1 ) sexual dimorphism in normal functional development of IFNs based on 259 participants (139 (F)emale vs. 120 (M)ale) who were no-tolow drinkers throughout this period; 2) sex-specific IFN trajectories linked to alcohol dose based on 38 no-to-low drinkers and 38 adolescents of the same sex and who exceeded the drinking criteria throughout the study; and an exploratory analysis based on all four matched data sets; 3) gender-specific alcohol dose effects mediated by impulsivity on IFN connectivity in all 526 NCANDA participants. The color scheme for labelling data sets will also be used for labelling the plots in the other figures.

Fig 2. Shown in blue are the regions with significant sex differences (two-sided $p<0.05$ after FWE correction for number of voxels and IFNs) between the average connectivity maps of 139 no-to-low drinkers girls and 120 boys (see also Fig. 1). Effects were detected in 6 IFNs, whose hubs (in yellow) are displayed on top of the SRI24 template.

Figure 3. (a) Significant sex differences on the slope maps of 259 no-to-low drinkers were detected in the inferior occipital network. (b, c) Post-hoc analysis examined the sex difference with respect to the average connectivity and slope within the detected cluster (red). (d) Linear mixed effect models fitted to the longitudinal rs-fMRIs of no-to-low drinkers revealed that boys had a decreasing developmental trajectory of functional connectivity in the detected cluster.

Figure 4. (a) Significant alcohol effects on the average connectivity maps of 38 moderate-tohigh and 38 no-to-low drinking girls were detected in the sensorimotor network. Average functional connectivity inside the detected cluster exhibited a graded dose effect in girls only. The amount of disruption was ranked from no-to-low, transitioning, to moderate-to-high girls (b, c). Connectivity within the cluster also significantly correlated with alcohol consumption among girls with non-zero history (d). This girl-specific correlation was significantly mediated by sensation seeking (UPPSP-SSS) (e).

Figure 5. (a) Significant alcohol effects on the average functional connectivity maps of 76 moderate-to-high and 76 no-to-low drinking drinkers were detected in the motor network. Average functional connectivity inside the detected cluster exhibited a stronger graded dose effect in girls, where the amount of disruption was ranked from no-to-low, transitioning, to moderate-to-high drinkers (b, c). Connectivity within the cluster significantly correlated with alcohol consumption among girls with non-zero history and showed trend-level correlation for 
boys (d). This girl-specific correlation was mediated by sensation seeking (UPPSP-SSS) on a trend-level (e).

Figure 6. (a) Significant alcohol effects on slope maps of 76 moderate-to-high and 76 no-to-low drinkers were detected in the inferior temporo-parieto-frontal network. The slope inside the detected cluster showed a dose effect (b, c) and a significant correlation with alcohol consumption between baseline and last visits (d) in both sexes.

This article is protected by copyright. All rights reserved. 


\section{Analysis Groups}

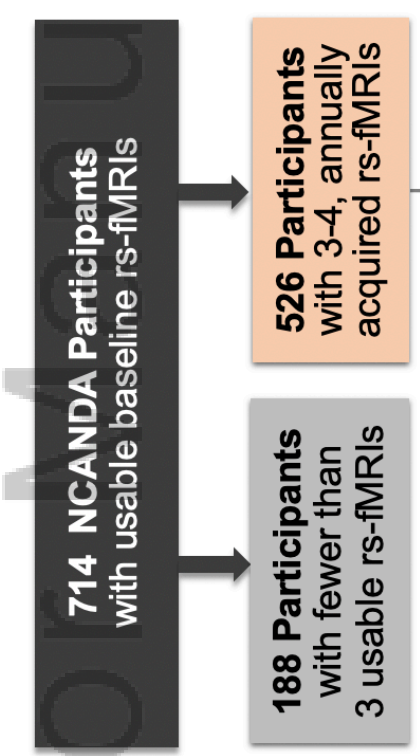

3 Drinking Groups

No-low: $139 \mathrm{~F}+120 \mathrm{M}$

Transitioners: $94 \mathrm{~F}+88 \mathrm{M}$

Moderate-High: $45 \mathrm{~F}+40 \mathrm{M}$
Testing Objective

Hypothesis 1

No-low drinkers $139 \mathrm{~F}$ vs. $120 \mathrm{M}$
Describe sex differences in normal IFN development

\section{Hypothesis 2}

Identify cluster of voxels where IFN trajectories are effected by alcohol

F: 38 no-low vs. 38 moderate-high

M: 38 no-low vs. 38 moderate-high

ADB_12914_fig1.tif 
Average Functional Connectivity No-to-low Drinking Group

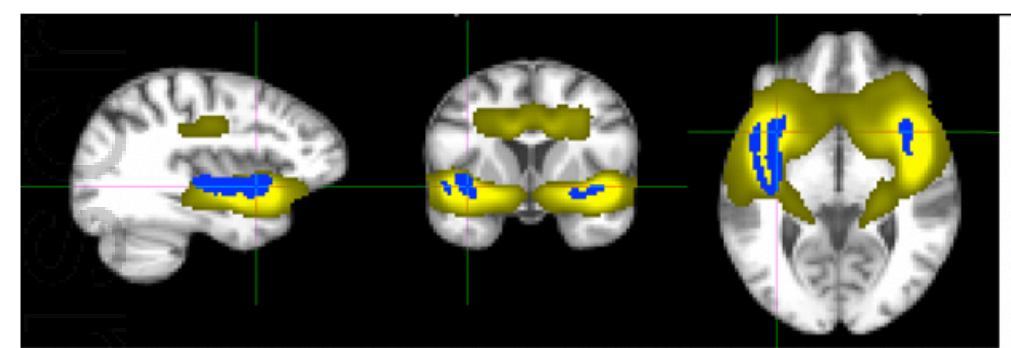

Limbic Hippocampal Network

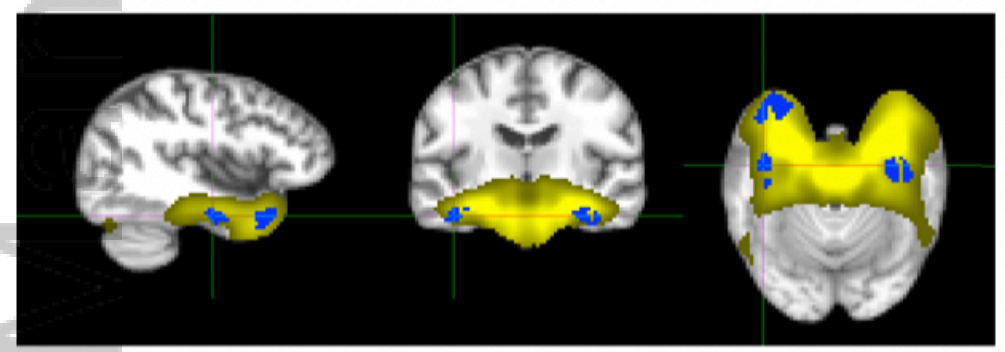

Emotion Network

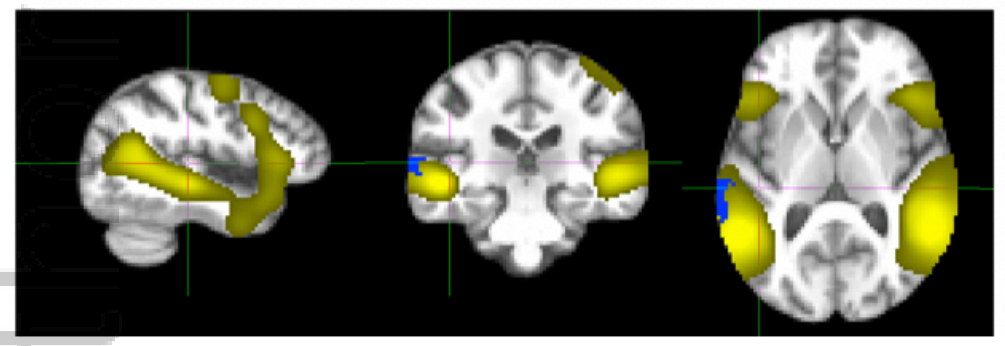

Inferior Temporo-parieto-frontal Network

120 no-to-low boys > 139 no-to-low girls

ADB_12914_fig2.tif

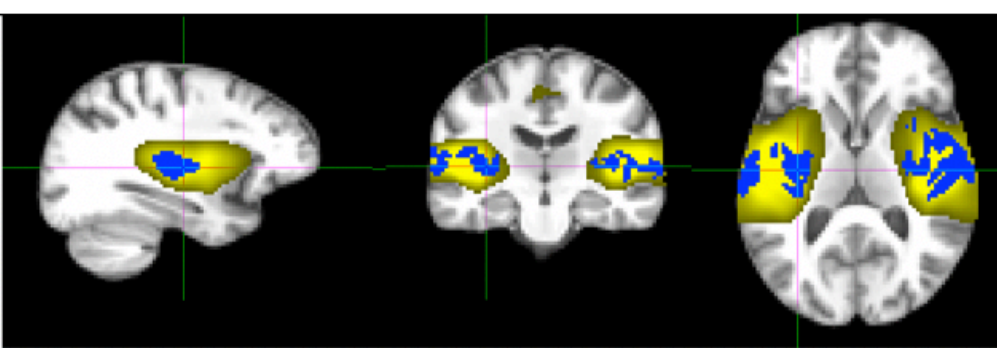

Auditory Network

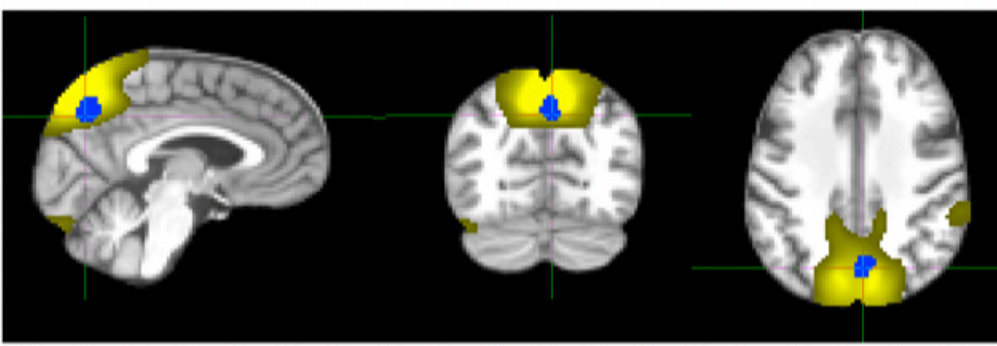

Precuneus Network

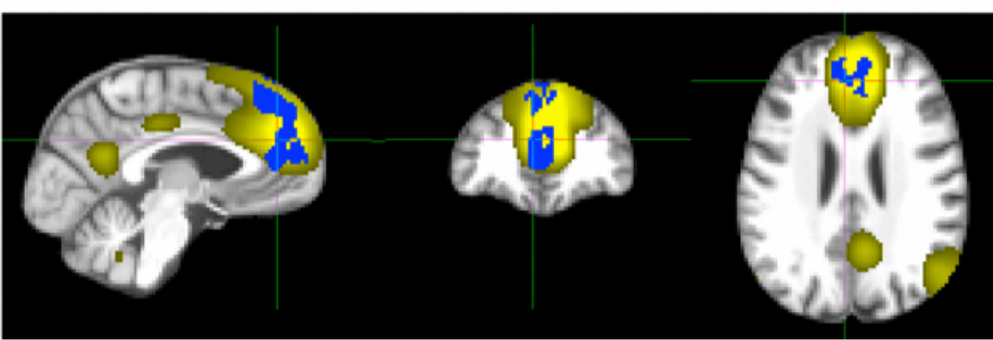

Dorsal Default Mode Network

3 Z-score of IFN 10 
Inferior Occipital Network

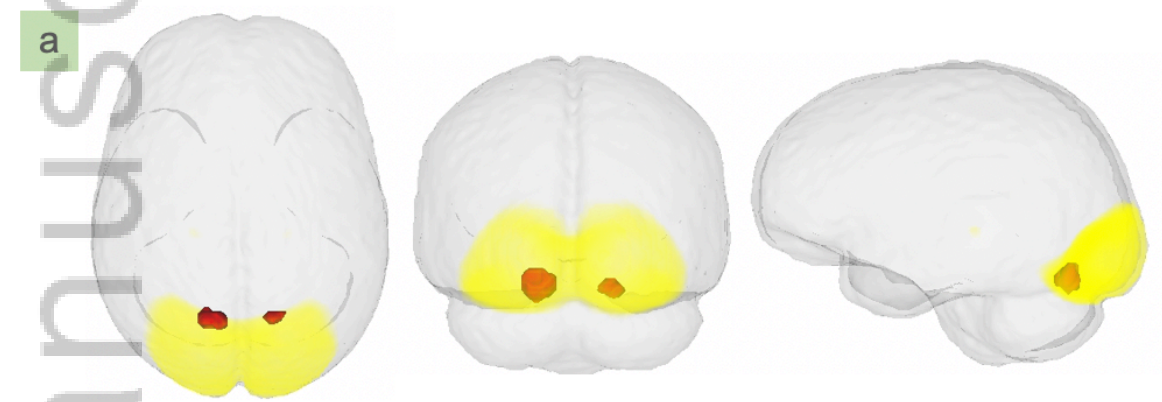

139 no-to-low girls > 120 no-to-low boys (slope)

b

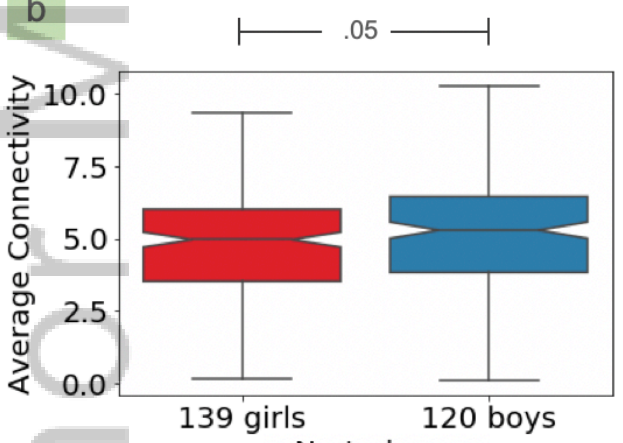

No-to-low
C

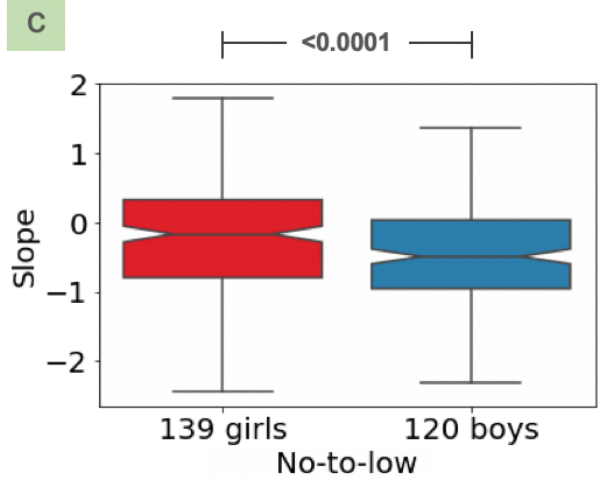

ADB_12914_fig3.tif

\section{d}

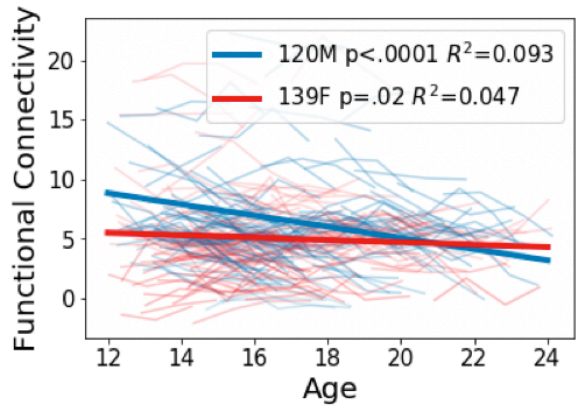

This article is protected by copyright. All rights reserved. 


\section{Sensorimotor Network}

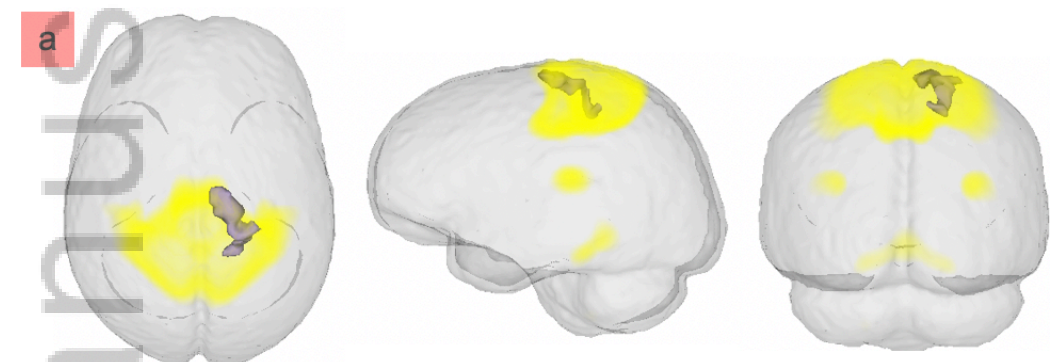

$\square 38$ moderate-to-high girls > 38 no-to-low girls (Avg Connectivity)
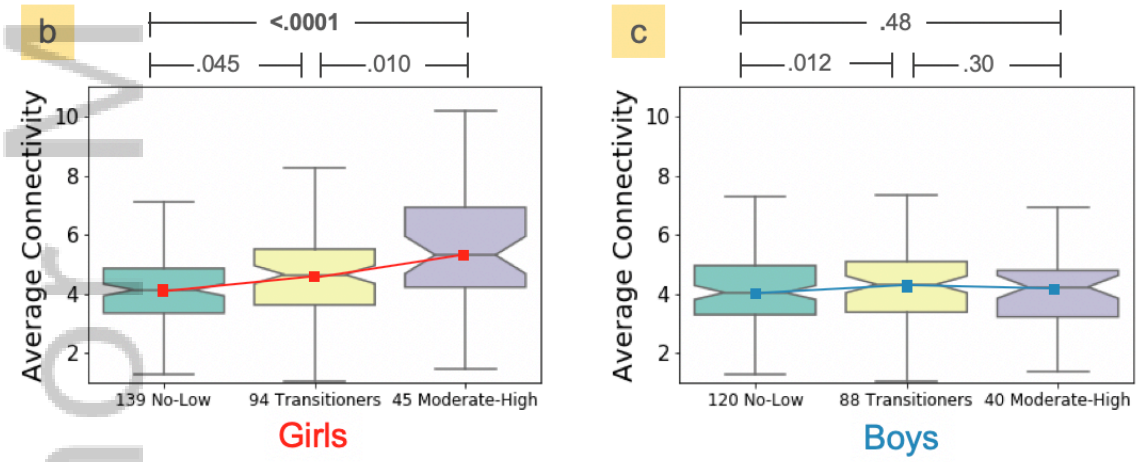

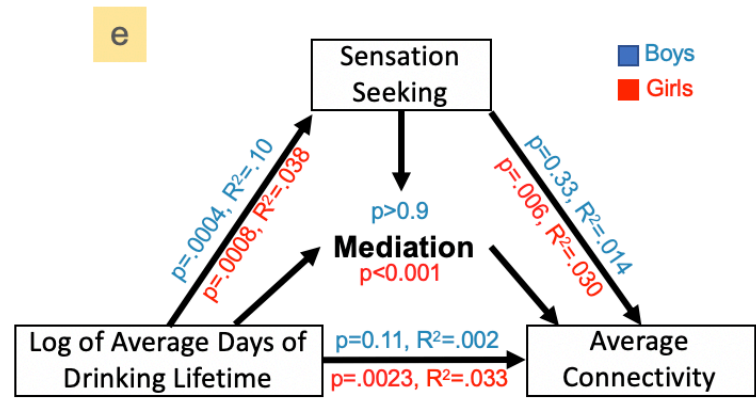

d

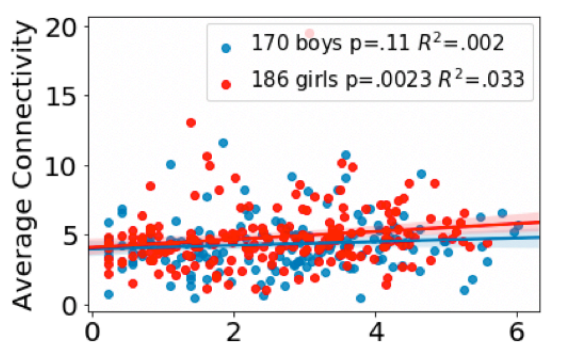

Log of Average Days of Drinking Lifetime

ADB_12914_fig4.tif 


\section{Motor Network}
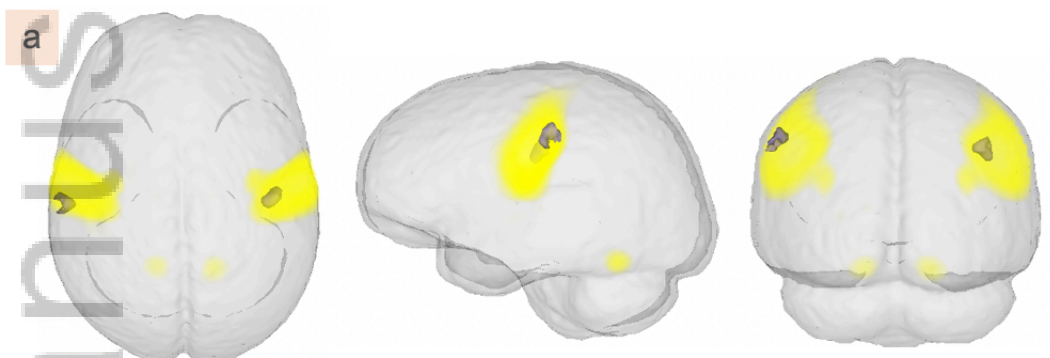

$\square 76$ moderate-to-high > 76 no-to-low (Avg Connectivity; boys \& girls)
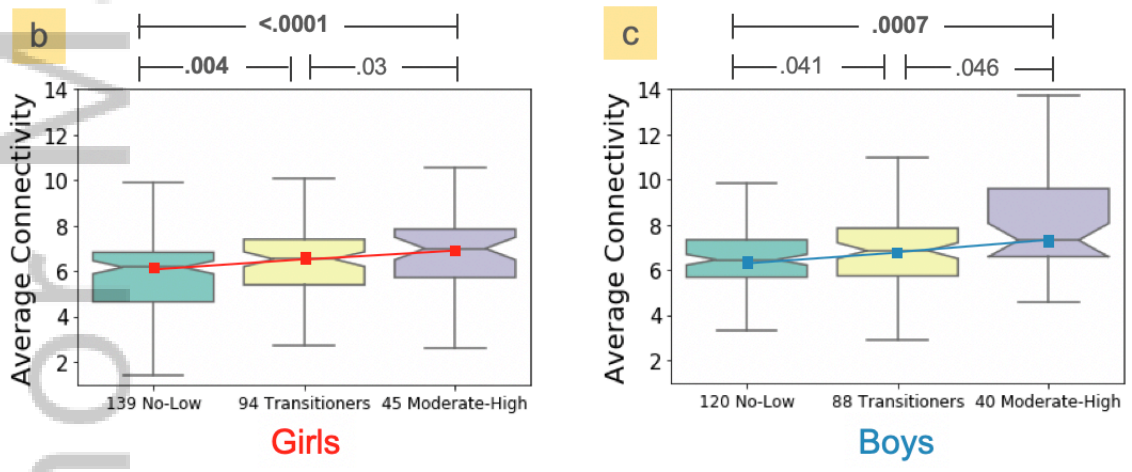

ADB_12914_fig5.tif

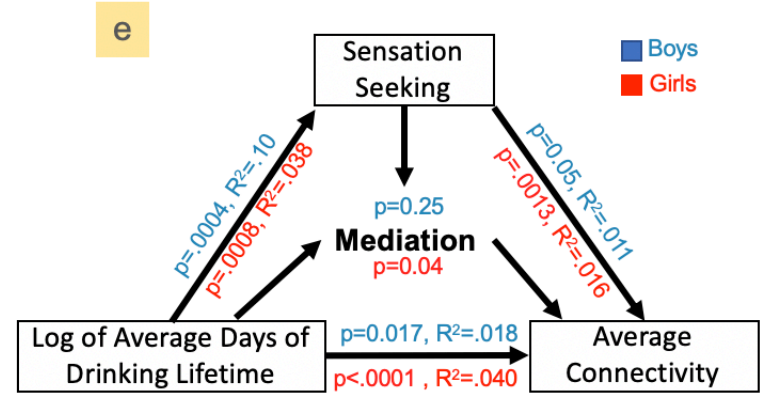

d

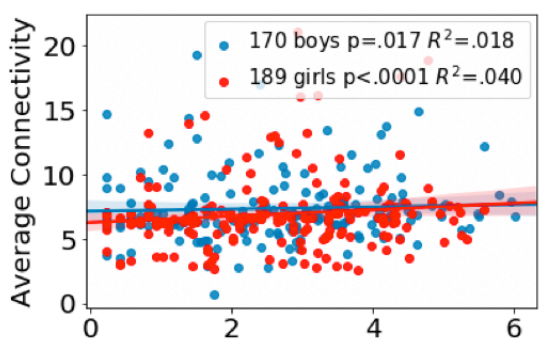

Log of Average Days of Drinking Lifetime 


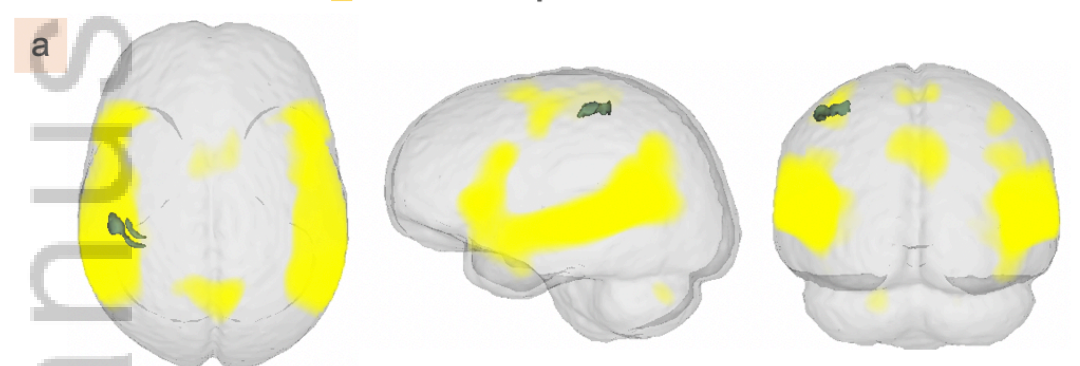

76 no-to-low > 76 moderate-to-high (Slope; boys \& girls)
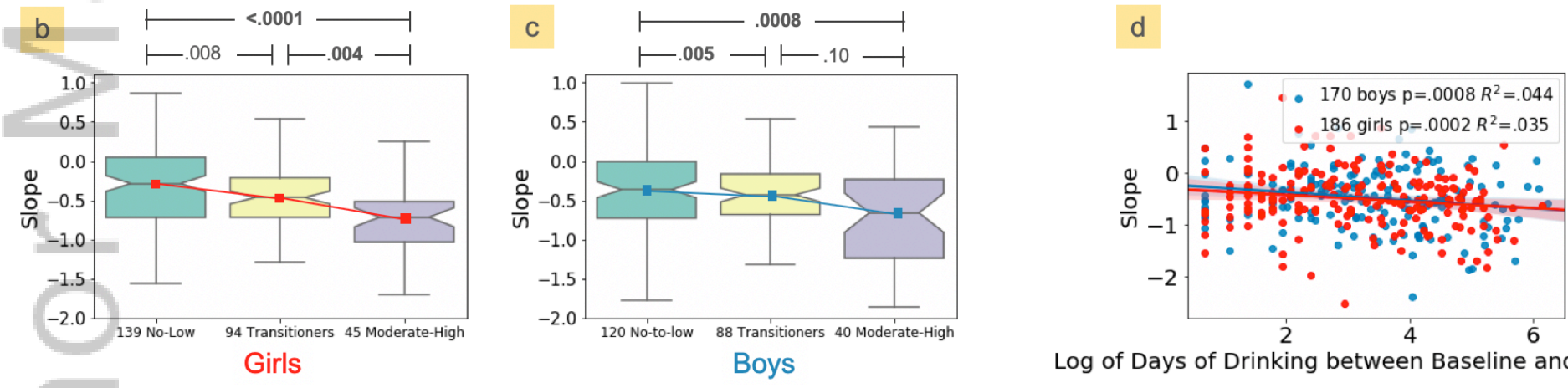

Log of Days of Drinking between Baseline and Last Visits

ADB_12914_fig6.tif

This article is protected by copyright. All rights reserved. 


\section{University Library}

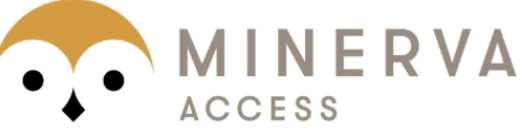

A gateway to Melbourne's research publications

Minerva Access is the Institutional Repository of The University of Melbourne

\section{Author/s:}

Zhao, Q;Sullivan, E;Muller-Oehring, EM;Honnorat, N;Adelil, E;Podhajsky, S;Baker, FC;Colrain, IM;Prouty, D;Tapert, SF;Brown, SA;Meloy, MJ;Brumback, T;Nagel, BJ;Morales, AM;Clark, DB;Luna, B;De Bellis, MD;Voyvodic, JT;Nooner, KB;Pfefferbaunn, A;Pohl, KM

Title:

Adolescent alcohol use disrupts functional neurodevelopment in sensation seeking girls

Date:

2020-05-19

\section{Citation:}

Zhao, Q., Sullivan, E., Muller-Oehring, E. M., Honnorat, N., Adelil, E., Podhajsky, S., Baker, F. C., Colrain, I. M., Prouty, D., Tapert, S. F., Brown, S. A., Meloy, M. J., Brumback, T., Nagel, B. J., Morales, A. M., Clark, D. B., Luna, B., De Bellis, M. D., Voyvodic, J. T. ,... Pohl, K. M. (2020). Adolescent alcohol use disrupts functional neurodevelopment in sensation seeking girls. ADDICTION BIOLOGY, 26 (2), https://doi.org/10.1111/adb.12914.

Persistent Link:

http://hdl.handle.net/11343/275767 